\title{
Thermoelectric Properties of Sr-Ru-O Compounds Prepared by Spark Plasma Sintering
}

\author{
Nittaya Keawprak, Rong Tu and Takashi Goto \\ Institute for Materials Research, Tohoku University, Sendai 980-8577, Japan
}

\begin{abstract}
$\mathrm{Sr}-\mathrm{Ru}-\mathrm{O}$ in the ratio of $\mathrm{Ru}$ to $\mathrm{Sr}\left(R_{\mathrm{Ru} / \mathrm{Sr}}\right)$ from 0.5 to 1.2 were prepared by spark plasma sintering (SPS) and the effect of composition on the electrical conductivity $(\sigma)$, thermal conductivity $(\kappa)$ and Seebeck coefficient $(S)$ was investigated. All compositions yielded dense sintered mass with around $90-100 \%$ of a theoretical density. $\mathrm{SrRuO}_{3}$ and $\mathrm{Sr}_{2} \mathrm{RuO}_{4}$ in a single phase were obtained at $R_{\mathrm{Ru} / \mathrm{Sr}}=1.0$ and 0.5 , respectively. The second phases were identified, i.e., $\mathrm{RuO}_{2}$ and $\mathrm{Ru}$ at $R_{\mathrm{Ru} / \mathrm{Sr}}>1.0$ and $\mathrm{Sr}_{3} \mathrm{Ru}_{2} \mathrm{O}_{7}$ and $\mathrm{Sr}_{2} \mathrm{RuO}_{4}$ at $R_{\mathrm{Ru} / \mathrm{Sr}}<1.0$. The $\sigma$ increased with increasing $R_{\mathrm{Ru} / \mathrm{Sr}}$ in the $R_{\mathrm{Ru} / \mathrm{Sr}}$ range from 0.8 to 1.2 at room temperature exhibiting a metallic behavior, whereas the $\sigma$ showed a semiconducting behavior at $R_{\mathrm{Ru} / \mathrm{Sr}}=0.5$. The $\kappa$ was around 2 to $7 \mathrm{Wm}^{-1} \mathrm{~K}^{-1}$ at $R_{\mathrm{Ru} / \mathrm{Sr}}=0.8$ to 1.2 at room temperature and slightly increased with increasing temperature and $R_{\mathrm{Ru} / \mathrm{Sr}}$. The $\kappa$ decreased with increasing temperature at $R_{\mathrm{Ru} / \mathrm{Sr}}=0.5$. The $S$ was around $25-40 \mu \mathrm{V} \mathrm{K}-1$ at room temperature, almost independent of compositions. The $S$ slightly decreased with temperature at $R_{\mathrm{Ru} / \mathrm{Sr}}=0.8$ to 1.0 , whereas the $S$ increased with temperature and showed a maximum around 500 to $600 \mathrm{~K}$ at $R_{\mathrm{Ru} / \mathrm{Sr}}=1.2$. The $S$ significantly decreased with increasing temperature at $R_{\mathrm{Ru} / \mathrm{Sr}}=0.5$. The highest dimensionless figure of merit $(Z T)$ was 0.06 at $R_{\mathrm{Ru} / \mathrm{Sr}}=1.2$ at $600 \mathrm{~K}$. [doi:10.2320/matertrans.MRA2007230]
\end{abstract}

(Received October 2, 2007; Accepted December 4, 2007; Published January 23, 2008)

Keywords: Strontium ruthenate, thermoelectricity, spark plasma sintering

\section{Introduction}

The strontium ruthenates can be considered as members of Ruddlesdon-Popper series, $\mathrm{Sr}_{n+1} \mathrm{Ru}_{n} \mathrm{O}_{3 n+1}(n=1,2,3$ and $\infty)$, where $n$ is the number of corner sharing $\mathrm{RuO}_{6}$ octahedra layers separated by $\mathrm{SrO}$ layers. The distortion degree of $\mathrm{RuO}_{6}$ octahedra decreases with increasing $n$ due to the increase in the overlap of $\mathrm{Ru}-4 \mathrm{~d}$ and $\mathrm{O}-2 \mathrm{p}$ orbitals. The $\mathrm{Sr}_{n+1} \mathrm{Ru}_{n} \mathrm{O}_{3 n+1}$ has different electrical conductivity $(\sigma)$ in $c$ direction and $a b$ plane. The anisotropy of $\sigma$ decreases with increasing $n .^{1)}$ The most widely studied compounds are infinite layered $(n=\infty) \mathrm{SrRuO}_{3}$ and single layered $(n=1)$ $\mathrm{Sr}_{2} \mathrm{RuO}_{4} . \mathrm{SrRuO}_{3}$ has an orthorhombically distorted perovskite of the $\mathrm{GdFeO}_{3}$ type structure with a space group of Pbnm at 10 to $800 \mathrm{~K}^{2)}$ However, the orthorhombicity decreases significantly above room temperature showing a tetragonal structure until $950 \mathrm{~K}$, and then transforms into a cubic perovskite structure. ${ }^{2-4)} \mathrm{SrRuO}_{3}$ shows a metallic electrical conduction. Capogna et al. ${ }^{5)}$ reported that the electrical conductivity of $\mathrm{SrRuO}_{3}$ increased from $5 \times 10^{5}$ to $90 \times 10^{5} \mathrm{Sm}^{-1}$ with decreasing temperature from room temperature to $5 \mathrm{~K}$. $\mathrm{SrRuO}_{3}$ has been used as a substrate for deposition of $\mathrm{YBa}_{2} \mathrm{Cu}_{3} \mathrm{O}_{7-x}$ (Y123) film and high temperature electrodes due to its excellent electrical conductivity. ${ }_{6}^{6,7)}$ $\mathrm{Sr}_{2} \mathrm{RuO}_{4}$ has a body-centered tetragonal $\mathrm{K}_{2} \mathrm{NiF}_{4}$ structure ${ }^{8)}$ having a superconduction below $1 \mathrm{~K} . \mathrm{Sr}_{2} \mathrm{RuO}_{4}$ single crystal shows metallic conduction behavior in the $a b$ plane and has a significant anisotropy in $a b$ plane and $c$ direction $\left(\sigma_{\mathrm{ab}} / \sigma_{\mathrm{c}}=\right.$ 220 at room temperature).$^{9)}$ Chandrasekaran et al. ${ }^{10)}$ reported that $\mathrm{Sr}_{2} \mathrm{RuO}_{4}$ exhibited semiconducting behavior between 15 and $300 \mathrm{~K}$ and the electrical conductivity changed with the oxygen defect of the $\mathrm{Sr}_{2} \mathrm{RuO}_{4} \cdot \mathrm{Sr}_{2} \mathrm{RuO}_{4}$ has been applied as a lattice matching material of $\mathrm{YBa}_{2} \mathrm{Cu}_{3} \mathrm{O}_{7}$ in a wide temperature range $\mathrm{f}^{7,8,11)}$ since its lattice parameters are almost independent of temperature. ${ }^{2)}$

Recently, strontium ruthenates have also been proposed as potential thermoelectric materials due to their high electrical conductivity and Seebeck coefficient. Maekawa et al. reported $\mathrm{SrRuO}_{3}$ had high electrical conductivity and Seebeck coefficient. Zheng et al. ${ }^{12)}$ reported the Seebeck coefficient of single crystal $\mathrm{Sr}_{2} \mathrm{RuO}_{4}$ of $a b$ plane increased from 0.1 to $9.0 \mu \mathrm{V} \mathrm{K}^{-1}$ with increasing temperature from 9 to $260 \mathrm{~K}$. However, the electrical and thermoelectric properties were studied mainly at low temperatures by using single crystals. No study on thermoelectric properties of polycrystalline Sr$\mathrm{Ru}-\mathrm{O}$ compounds was reported. This may be caused of the difficulty to obtain dense body by conventional sintering. ${ }^{13)}$

Spark plasma sintering (SPS) has been demonstrated as an effective method to densify hardly sinterable powder. In the present study, dense Sr-Ru-O body was prepared by spark plasma sintering (SPS), and the effect of $\mathrm{Ru} / \mathrm{Sr}$ ratio $\left(R_{\mathrm{Ru} / \mathrm{Sr}}\right)$ on the crystal structure, electrical conductivity, thermal conductivity, Seebeck coefficient and $Z T$ value of Sr-Ru-O compounds was investigated.

\section{Experimental}

Sr-Ru-O powders were synthesized by solid state reaction using $\mathrm{SrCO}_{3}(99.99 \%)$ and $\mathrm{RuO}_{2}(99.99 \%)$ in the ratio of $\mathrm{Ru}$ to $\mathrm{Sr}\left(R_{\mathrm{Ru} / \mathrm{Sr}}\right)$ between 0.5 and 1.4. The powder mixtures were calcined at $1273 \mathrm{~K}$ for $43.2 \mathrm{ks}$ in air. The calcined powder was pressed in a graphite die and sintered by SPS at $1523 \mathrm{~K}$ for $0.3 \mathrm{ks}$ in a vacuum at a load of $80 \mathrm{MPa}$. The sintered body was cut to $2 \times 2 \times 10 \mathrm{~mm}$ for the measurement of electrical conductivity by a d.c. 4-probe method and Seebeck coefficient by a thermoelectric power $(\Delta \mathrm{E})$-temperature difference $(\Delta T)$ method. A disk shape specimen of $10 \mathrm{~mm}$ in diameter and $1 \mathrm{~mm}$ in thickness was employed to measure thermal conductivity by a laser flash method (ULVAC TC7000). All electrical and thermal measurements were conducted from room temperature (RT) to $1023 \mathrm{~K}$. The crystal phase was examined by X-ray diffraction (Rigaku Geigerflex). The density (d) was determined by an Archimedes method. 


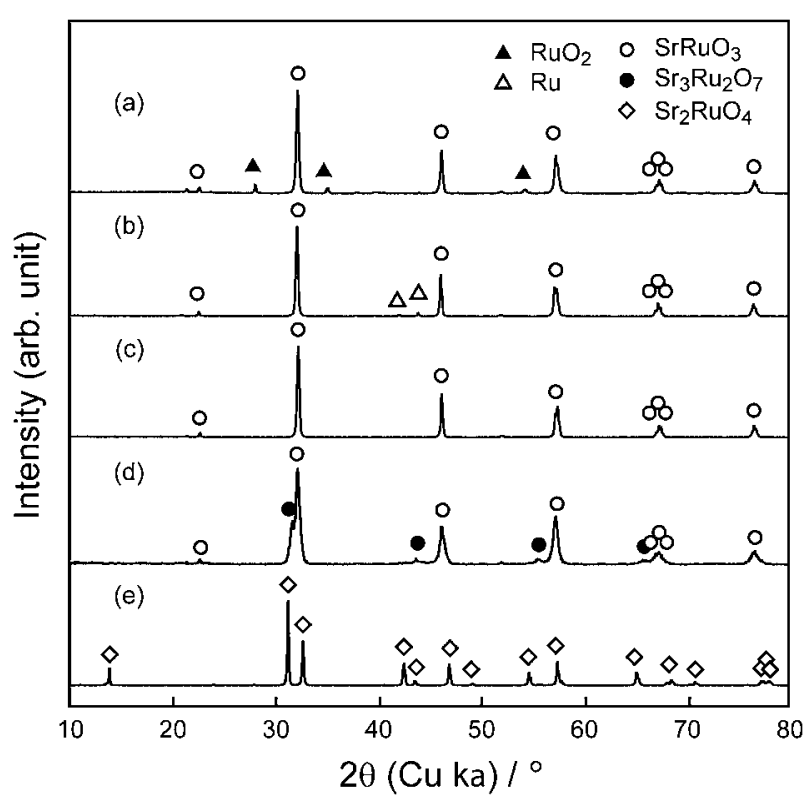

Fig. 1 XRD pattern of Sr-Ru-O compounds with various $R_{\mathrm{Ru} / \mathrm{Sr}}=1.2$ (a), 1.1 (b), 1.0 (c), 0.8 (d) and 0.5 (e).

\section{Results and Discussion}

Figure 1 shows the XRD patterns of $\mathrm{Sr}-\mathrm{Ru}-\mathrm{O}$ compounds at $R_{\mathrm{Ru} / \mathrm{Sr}}=0.5$ to $1.2 . \mathrm{SrRuO}_{3}$ and $\mathrm{Sr}_{2} \mathrm{RuO}_{4}$ in a single phase were obtained at $R_{\mathrm{Ru} / \mathrm{Sr}}=1.0$ (Fig. 1(c)) and 0.5 (Fig. 1(e)), respectively. Second phases of $\mathrm{RuO}_{2}$ and $\mathrm{Ru}$ with the main phase of $\mathrm{SrRuO}_{3}$ were identified at $R_{\mathrm{Ru} / \mathrm{Sr}} \geq 1.2$ (Fig. 1(a)) and $R_{\mathrm{Ru} / \mathrm{Sr}}=1.1$ (Fig. 1(b)), respectively. A small amount of $\mathrm{Sr}_{3} \mathrm{Ru}_{2} \mathrm{O}_{7}$ and/or $\mathrm{Sr}_{2} \mathrm{RuO}_{4}$ were detected at $R_{\mathrm{Ru} / \mathrm{Sr}}<1.0$ (Fig. 1(d)). Jacob et al. ${ }^{14)}$ have reported that $\mathrm{SrRuO}_{3}$ formed at lower temperatures $(T<1573 \mathrm{~K})$, and $\mathrm{Sr}_{2} \mathrm{RuO}_{4}$ and $\mathrm{Sr}_{3} \mathrm{Ru}_{2} \mathrm{O}_{7}$ formed at higher temperature $(T>1573 \mathrm{~K})$. $\mathrm{Sr}_{4} \mathrm{Ru}_{3} \mathrm{O}_{10}$ would form at higher than $1723 \mathrm{~K}$. In the present study, $\mathrm{Sr}_{4} \mathrm{Ru}_{3} \mathrm{O}_{10}$ was not identified due to the low sintering temperature.

Figure 2 demonstrates the effect of $R_{\mathrm{Ru} / \mathrm{Sr}}$ on the lattice parameters of $\mathrm{SrRuO}_{3}$ phase. At $R_{\mathrm{Ru} / \mathrm{Sr}}=0.9$ to 1.4 , the lattice parameters of $a, b$ and $c$ were independent of $R_{\mathrm{Ru} / \mathrm{Sr}}$ and were constant values of $0.5570,0.7851$ and $0.5533 \mathrm{~nm}$, respectively. The lattice parameters at $R_{\mathrm{Ru} / \mathrm{Sr}}=0.7$ and 0.8 were not clearly determined, due to too broad XRD peaks. It is difficult to keep the standard deviation of d-values within $0.1 \%$ by using broad peaks. Then, lattice parameters at $R_{\mathrm{Ru} / \mathrm{Sr}}=0.7$ and 0.8 was not presented. Although $\mathrm{CaRuO}_{3}$ has a solid solution range of the ratio of $\mathrm{Ru}$ to $\mathrm{Ca}\left(R_{\mathrm{Ru} / \mathrm{Ca}}\right)=$ 0.7 to $\left.1.0,{ }^{15}\right) \mathrm{SrRuO}_{3}$ should be a stoichiometric compound. The lattice parameters of $\mathrm{Sr}_{2} \mathrm{RuO}_{4}$ were $a=b=0.3869$ and $c=1.2742 \mathrm{~nm}$, almost the same as the reference $(a=b=$ 0.38694 and $c=1.2746 \mathrm{~nm}) .{ }^{16}$ )

Figure 3 presents the temperature dependence of the electrical conductivity $(\sigma)$ of $\mathrm{Sr}-\mathrm{Ru}-\mathrm{O}$ compounds at various $R_{\mathrm{Ru} / \mathrm{Sr}}$. The relative densities of all specimens were around 96 to $99 \%$. The $\sigma$ decreased with increasing temperature at $R_{\mathrm{Ru} / \mathrm{Sr}}>0.5$ showing a metallic conduction, whereas the $\sigma$ at $R_{\mathrm{Ru} / \mathrm{Sr}}=0.5$ slightly increased with temperature showing a semiconducting conduction. $\mathrm{SrRuO}_{3}$ in a single phase $\left(R_{\mathrm{Ru} / \mathrm{Sr}}=1.0\right)$ had a $\sigma$ of $3 \times 10^{5} \mathrm{Sm}^{-1}$ at $293 \mathrm{~K}$, which was

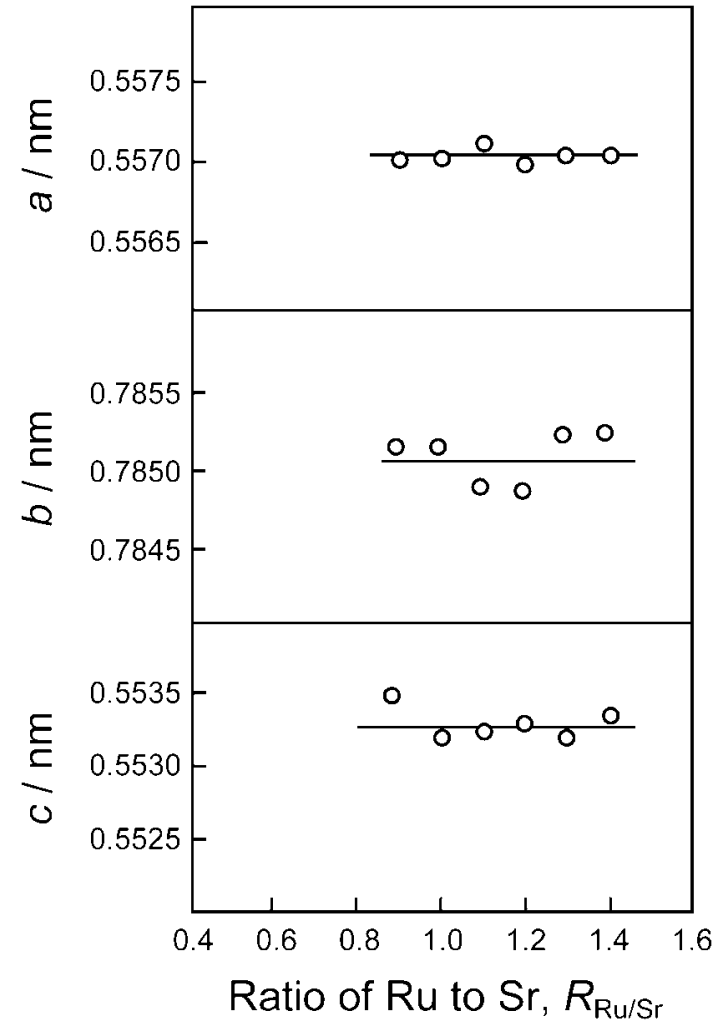

Fig. 2 Lattice parameters of $\mathrm{SrRuO}_{3}$ compound.

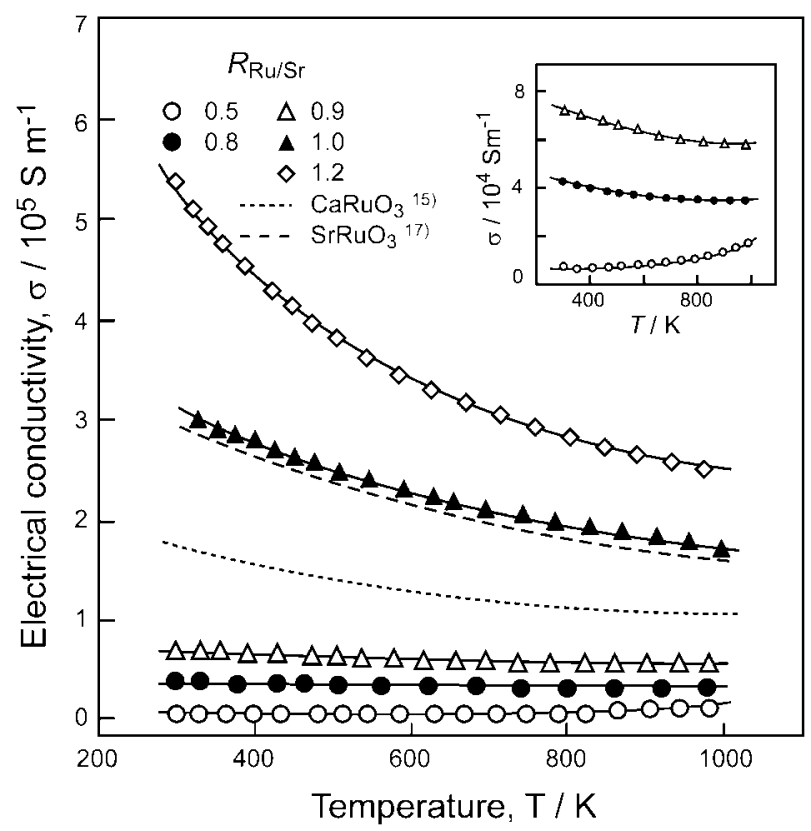

Fig. 3 Temperature dependence of electrical conductivity of Sr-Ru-O compounds.

almost the same as that reported by Maekawa. ${ }^{17)}$ The $\sigma$ of $\mathrm{SrRuO}_{3}$ was higher than that of $\mathrm{CaRuO}_{3} .{ }^{16)} \mathrm{Cox}$ et al. ${ }^{18)}$ have studied the electrical conduction of $\mathrm{SrRuO}_{3}$ and $\mathrm{CaRuO}_{3}$ by photoelectron spectroscopy. $\mathrm{SrRuO}_{3}$ showed higher electrical conductivity because of higher density of states at Fermi energy $\left(E_{\mathrm{F}}\right)$. Kobayashi et al. ${ }^{19)}$ have studied the relationship between crystal structure and electrical conductivity of $\mathrm{SrRuO}_{3}$ and $\mathrm{CaRuO}_{3}$ and reported that the distortion degree 


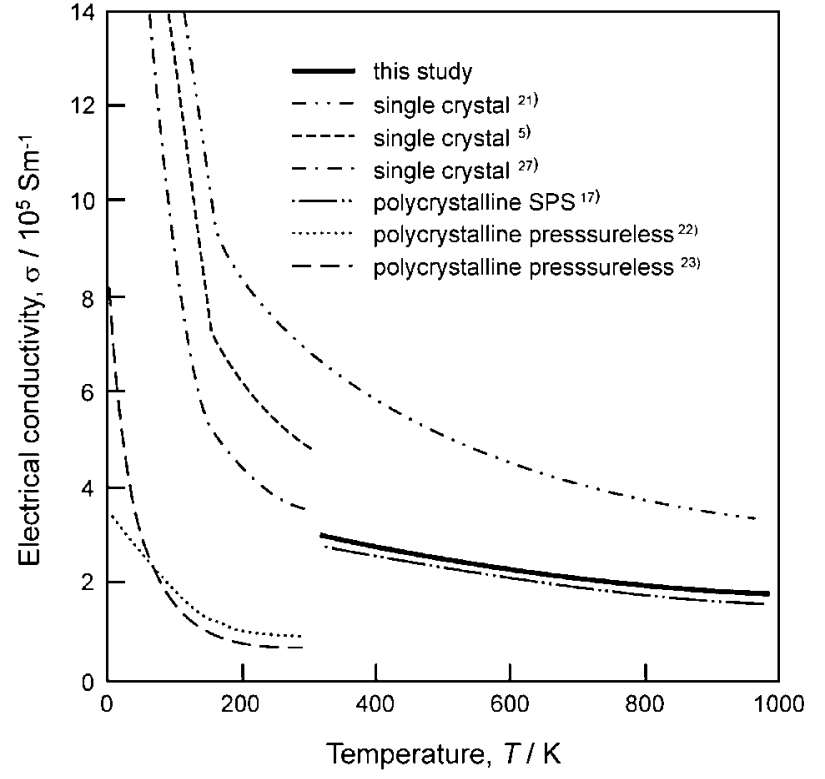

Fig. 4 Temperature dependence of single-crystalline and poly-crystalline $\mathrm{SrRuO}_{3}$.

and the angle of $\mathrm{Ru}-\mathrm{O}-\mathrm{Ru}$ bond of $\mathrm{CaRuO}_{3}$ was higher than those of $\mathrm{SrRuO}_{3}$, resulting in the lower electrical conductivity of $\mathrm{CaRuO}_{3}$. The $\sigma$ of $\mathrm{Sr}-\mathrm{Ru}-\mathrm{O}$ increased with increasing $R_{\mathrm{Ru} / \mathrm{Sr}}$. The high electrical conductivity at $R_{\mathrm{Ru} / \mathrm{Sr}}>1.0$ might be caused by the second phase of $\mathrm{RuO}_{2}\left(\sigma_{\mathrm{RuO} 2}=1.4 \times\right.$ $10^{6} \mathrm{Sm}^{-1}$ at $\left.293 \mathrm{~K}\right) .{ }^{15)}$ The $\sigma$ at $R_{\mathrm{Ru} / \mathrm{Sr}}<1.0$ presented a much lower values comparing with that of $R_{\mathrm{Ru} / \mathrm{Sr}} \geq 1.0$. This might be caused of the low $\sigma$ of $\mathrm{Sr}_{3} \mathrm{Ru}_{2} \mathrm{O}_{7}$ and $\mathrm{Sr}_{2} \mathrm{RuO}_{4}$ second phase $\left(\sigma\right.$ of $\mathrm{Sr}_{3} \mathrm{Ru}_{2} \mathrm{O}_{7}$ and $\mathrm{Sr}_{2} \mathrm{RuO}_{4}$ were $3.5 \times 10^{3}$ $\mathrm{Sm}^{-120)}$ and $5 \times 10^{3} \mathrm{Sm}^{-110)}$ at $\mathrm{RT}$, respectively). The $\sigma$ of $\mathrm{Sr}_{2} \mathrm{RuO}_{4}$ at room temperature was $7.2 \times 10^{3} \mathrm{Sm}^{-1}$ and much lower than that of $\mathrm{SrRuO}_{3}$.

Figure 4 shows the temperature dependence of electrical conductivity of single- and poly-crystalline $\mathrm{SrRuO}_{3}$ reported in literatures. All data exhibited a metallic behavior at the whole temperature. The $\sigma$ of the single-crystalline $\mathrm{SrRuO}_{3}{ }^{21)}$ was higher than that of poly-crystalline in the present study by a factor of 2 . The poly-crystalline $\mathrm{SrRuO}_{3}$ prepared by SPS in this study and that reported by Maekawa et al. ${ }^{17)}$ had higher $\sigma$ by factor of 3 than that prepared by pressureless sintering, ${ }^{22,23)}$ probably due to the high density.

Figure 5 shows the temperature dependence of the electrical conductivity of single- and poly-crystalline $\mathrm{Sr}_{2} \mathrm{RuO}_{4}$ in literatures. The $\sigma$ of $\mathrm{Sr}_{2} \mathrm{RuO}_{4}$ in this study exhibited a semiconducting behavior from RT to $1000 \mathrm{~K}$ $\left(7 \times 10^{3}\right.$ to $\left.1.6 \times 10^{4} \mathrm{Sm}^{-1}\right)$. So far, no studies on the $\sigma$ of $\mathrm{Sr}_{2} \mathrm{RuO}_{4}$ at high temperatures have been reported. The $\sigma$ of single crystalline $\mathrm{Sr}_{2} \mathrm{RuO}_{4}$ sharply decreased with increasing temperature at less than $100 \mathrm{~K}$, and showed significant anisotropic electrical conductivity between $a b$ plane and $c$ axis. The $\sigma$ of poly-crystalline $\mathrm{Sr}_{2} \mathrm{RuO}_{4}$ had intermediate values between $c$ direction and $a b$ plane. Chandrasekaran $e t$ al. reported that the $\sigma$ of poly-crystalline $\mathrm{Sr}_{2} \mathrm{RuO}_{4}$ prepared by a conventional sintering method increased with increasing temperature from $15 \mathrm{~K}$ to room temperature $(\sigma=4.8 \times$ $10^{3} \mathrm{Sm}^{-1}$ at RT). ${ }^{10)}$ This value was lower than our results.

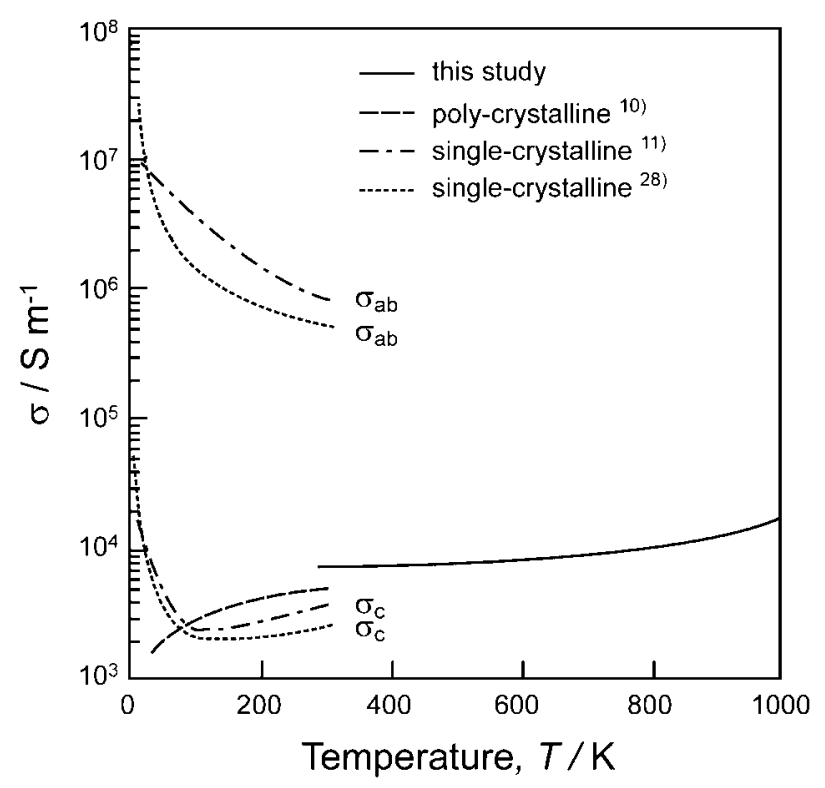

Fig. 5 Temperature dependence of single-crystalline and poly-crystalline $\mathrm{Sr}_{2} \mathrm{RuO}_{4}$.

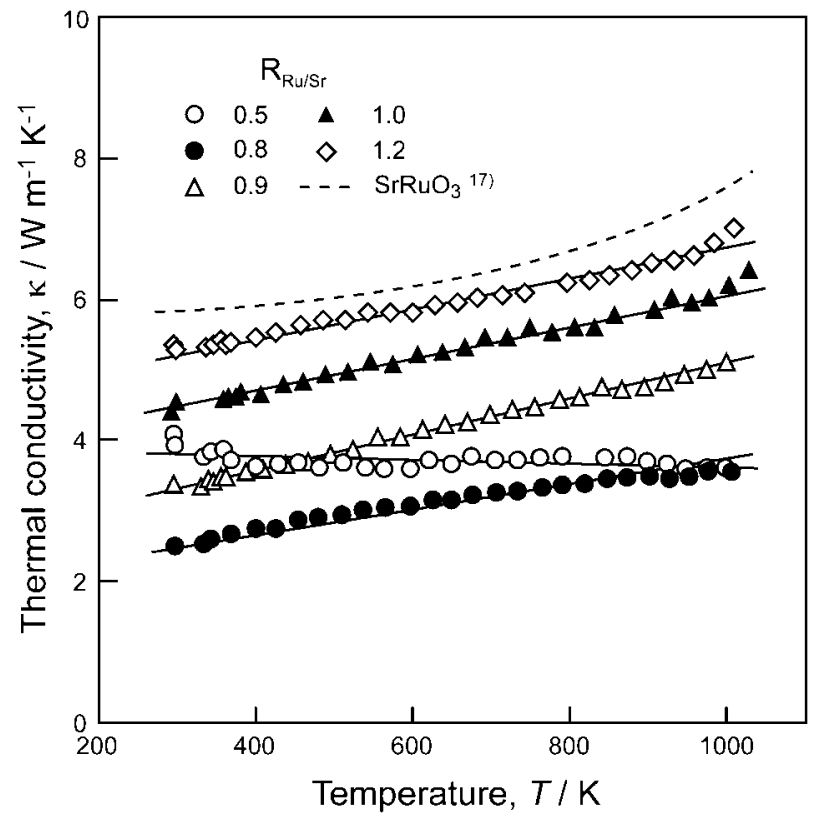

Fig. 6 Temperature dependence of thermal conductivity of Sr-Ru-O compounds.

Figure 6 shows the temperature dependence of thermal conductivity $(\kappa)$ of $\mathrm{Sr}-\mathrm{Ru}-\mathrm{O}$ compounds with various $R_{\mathrm{Ru} / \mathrm{Sr}}$. The $\kappa$ at $R_{\mathrm{Ru} / \mathrm{Sr}}=0.8$ to 1.2 increased with increasing temperature whereas that of $R_{\mathrm{Ru} / \mathrm{Sr}}=0.5$ slightly decreased with increasing temperature. The $\kappa$ at room temperature increased from 2.5 to $5.3 \mathrm{Wm}^{-1} \mathrm{~K}^{-1}$ with increasing $R_{\mathrm{Ru} / \mathrm{Sr}}$ from 0.8 to 1.2. This might be resulted from the second phase of $\mathrm{RuO}_{2}\left(\kappa=13 \mathrm{Wm}^{-1} \mathrm{~K}^{-1}\right),{ }^{15)} \mathrm{Sr}_{3} \mathrm{Ru}_{2} \mathrm{O}_{7}$ and $\mathrm{Sr}_{2} \mathrm{RuO}_{4}$. The $\kappa$ of $\mathrm{SrRuO}_{3}$ was ranged around 4.5 to $6.0 \mathrm{Wm}^{-1} \mathrm{~K}^{-1}$ at 293 to $1020 \mathrm{~K}$. Yamanaka et al. $^{24)}$ have studied many alkaline earth perovskites (e.g. $\mathrm{SrTiO}_{3}, \mathrm{SrZrO}_{3}, \mathrm{SrHfO}_{3}, \mathrm{BaZrO}_{3}$ and $\mathrm{SrRuO}_{3}$ ) and only $\mathrm{SrRuO}_{3}$ showed the increase of thermal conductivity with increasing temperature. This is consistent 


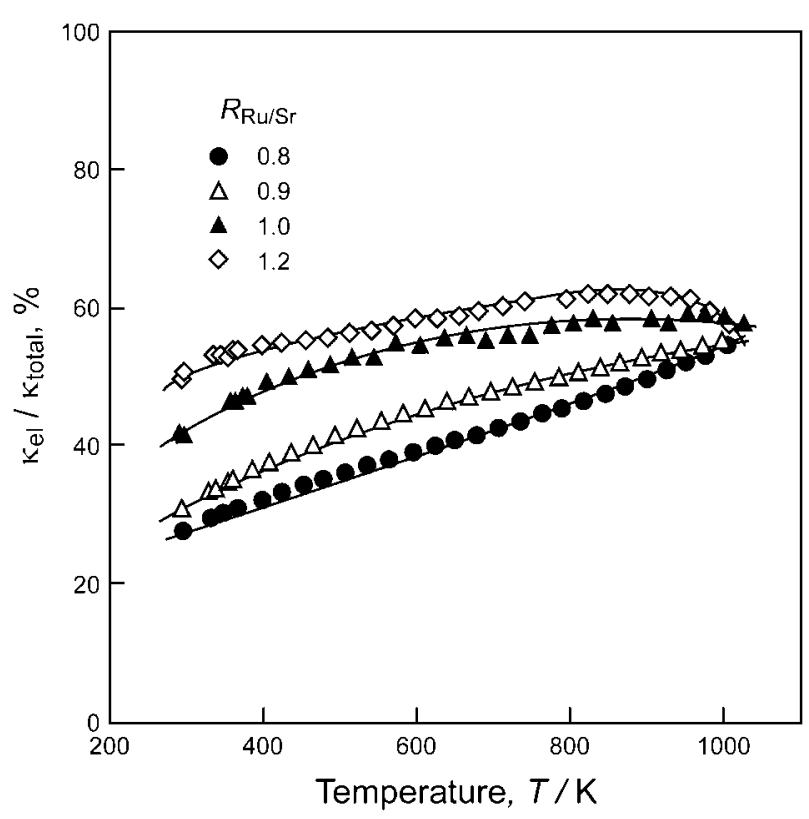

Fig. 7 Temperature dependence of fraction of electronic thermal conductivity of Sr-Ru-O compounds.

with our study, which might be caused by the complicated electronic structure of $\mathrm{SrRuO}_{3}$. Maekawa et al. ${ }^{17)}$ prepared $\mathrm{SrRuO}_{3}$ by SPS, and the $\kappa$ increased from 6 to $8 \mathrm{Wm}^{-1} \mathrm{~K}^{-1}$ with increasing temperature from RT to $1200 \mathrm{~K}$. These values were higher than those of the present study.

The total thermal conductivity $(\kappa)$ is composed of the phonon thermal conductivity $\left(\kappa_{\mathrm{ph}}\right)$ and electronic thermal conductivity $\left(\kappa_{\mathrm{el}}\right)$. The relationship between electrical conductivity and thermal conductivity can be described by equations (1) to (3).

$$
\begin{aligned}
\kappa & =\kappa_{\mathrm{el}}+\kappa_{\mathrm{ph}} \\
\kappa_{\mathrm{el}} & =L \sigma T \\
\kappa & =L \sigma T+\kappa_{\mathrm{ph}}
\end{aligned}
$$

where $L$ is a Lorenz number, $\sigma$ is the electrical conductivity and $T$ is an absolute temperature. According to eq. (2), at a specific temperature the ratio of the electrical and thermal conductivity is constant for a metallic conductor, called the Wiedemann-Franz law. The Lorenz number was calculated by the slope of $\kappa$ vs. $\sigma T$ plot as shown in eq. (3). The $L$ at $R_{\mathrm{Ru} / \mathrm{Sr}}=0.8,0.9,1.0$ and 1.2 were $5.58 \times 10^{-8}, 4.89 \times$ $10^{-8}, 2.09 \times 10^{-8}$ and $1.68 \times 10^{-8} \mathrm{WSK}^{-2}$, respectively, and decreased with increasing $R_{\mathrm{Ru} / \mathrm{Sr}}$. The difference of $L$ in this study may be resulted from the effect of secondary phases. The high $\sigma$ of secondary phase of $\mathrm{RuO}_{2}$ at $R_{\mathrm{Ru} / \mathrm{Sr}}>$ 1.0 may result in the low $L$ whereas the low $\sigma$ of secondary phase of $\mathrm{Sr}_{2} \mathrm{RuO}_{4}$ and $\mathrm{Sr}_{3} \mathrm{Ru}_{2} \mathrm{O}_{7}$ at $R_{\mathrm{Ru} / \mathrm{Sr}}<1.0$ may result in the high $L$. The $L$ of single-crystalline $\mathrm{SrRuO}_{3}$ was reported to be $1.63 \times 10^{-8} \mathrm{WSK}^{-225)}$ at low temperatures from 8 to $250 \mathrm{~K}$. The Lorenz number of common metallic material is $2.43 \times 10^{-8} \mathrm{WSK}^{-2}{ }^{26)}$ This value was almost coincided with that of $\mathrm{SrRuO}_{3}$ in this study. Figure 7 shows the fraction of electronic thermal conductivity $\left(\kappa_{\mathrm{el}}\right)$ in the total thermal conductivity of Sr-Ru-O compounds at $R_{\mathrm{Ru} / \mathrm{Sr}}=0.8$ to 1.2 . The $\kappa_{\mathrm{el}}$ of all specimens increased with increasing temperature. Although the $\sigma$ decreased with increasing temperature,

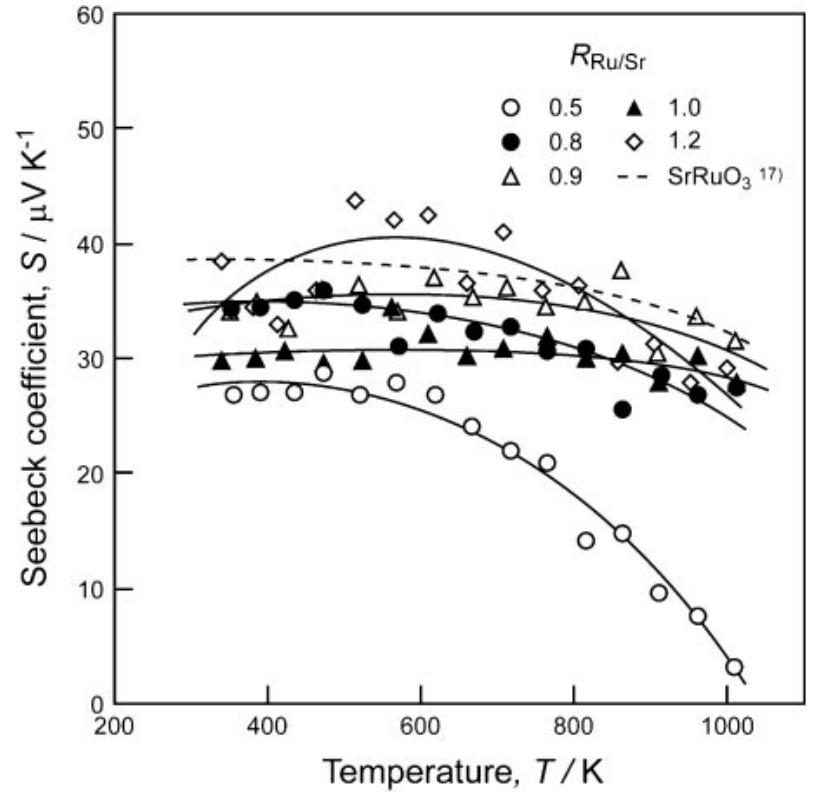

Fig. 8 Temperature dependence of Seebeck coefficient of Sr-Ru-O compounds.

the increase in $\kappa_{\mathrm{el}}$ with $T$ can be understood from eq. (2). The $\kappa_{\mathrm{el}}$ also increased with increasing $R_{\mathrm{Ru} / \mathrm{Sr}}$ due to the increase in $\sigma$. The fraction of $\kappa_{\mathrm{el}}$ in $\kappa$ at $R_{\mathrm{Ru} / \mathrm{Sr}}=1.0$ increased from 42 to $59 \%$ with increasing temperature from RT to $1000 \mathrm{~K}$. The fraction of $\kappa_{\mathrm{el}}$ at $R_{\mathrm{Ru} / \mathrm{Sr}}=1.2$ increased gradually from $50 \%$ at RT to $62 \%$ at $930 \mathrm{~K}$, indicating the heat can be dominently transported with holes. The fraction of $\kappa_{\mathrm{el}}$ at $R_{\mathrm{Ru} / \mathrm{Sr}}<1.0$ were less than $30 \%$ at room temperature implying the heat can be transported with phonons. Shepard et al. ${ }^{24)}$ have measured the $\kappa$ and $\sigma$ of $\mathrm{Sr}_{1-x} \mathrm{Ca}_{x} \mathrm{RuO}_{3}(x=0$ to 1 ), and reported the $\kappa_{\mathrm{el}}$ at $x=0\left(\mathrm{SrRuO}_{3}\right)$ was around $50 \%$ at room temperature. This was almost consistent with our results. $\mathrm{Sr}_{2} \mathrm{RuO}_{4}$ showed a semiconducting behavior, and then the Wiedemann-Franz law would not be applicable to $\mathrm{Sr}_{2} \mathrm{RuO}_{4}$.

Figure 8 shows the temperature dependence of Seebeck coefficient $(S)$ of $\mathrm{Sr}-\mathrm{Ru}-\mathrm{O}$ compounds at various $R_{\mathrm{Ru} / \mathrm{Sr}}$. All specimens showed positive Seebeck coefficient from RT to $1000 \mathrm{~K}$, consistent with the p-type conduction. The $S$ at $R_{\mathrm{Ru} / \mathrm{Sr}}=1.0$ was $30 \mu \mathrm{V} \mathrm{K}^{-1}$, almost independent of temperature. The $S$ at $R_{\mathrm{Ru} / \mathrm{Sr}}<1.0$ decreased with increasing temperature and increased with increasing $R_{\mathrm{Ru} / \mathrm{Sr}}$. At $R_{\mathrm{Ru} / \mathrm{Sr}}=1.2$, the $S$ increased with temperature and showed the highest value of $42 \mu \mathrm{V} \mathrm{K}^{-1}$ at $600 \mathrm{~K}$. The $S$ of $\mathrm{Sr}_{2} \mathrm{RuO}_{4}$ $\left(R_{\mathrm{Ru} / \mathrm{Sr}}=0.5\right)$ significantly decreased from 28 to $3 \mu \mathrm{V} \mathrm{K}^{-1}$ with increasing temperature from RT to $1000 \mathrm{~K}$. The $S$ of $\mathrm{Sr}_{2} \mathrm{RuO}_{4}$ showed common temperature dependence of semiconductors.

Figure 9 shows the temperature dependence of dimensionless thermoelectric figure of merit (ZT) calculated from eq. (4).

$$
Z T=S^{2} \sigma T / \kappa
$$

The $Z T$ at $R_{\mathrm{Ru} / \mathrm{Sr}}=0.8$ to 1.0 slightly increased with temperature, whereas that at $R_{\mathrm{Ru} / \mathrm{Sr}}=0.5$ decreased with increasing temperature. The $Z T$ at $R_{\mathrm{Ru} / \mathrm{Sr}}=1.2$ increased with increasing temperature and showed the highest value of 


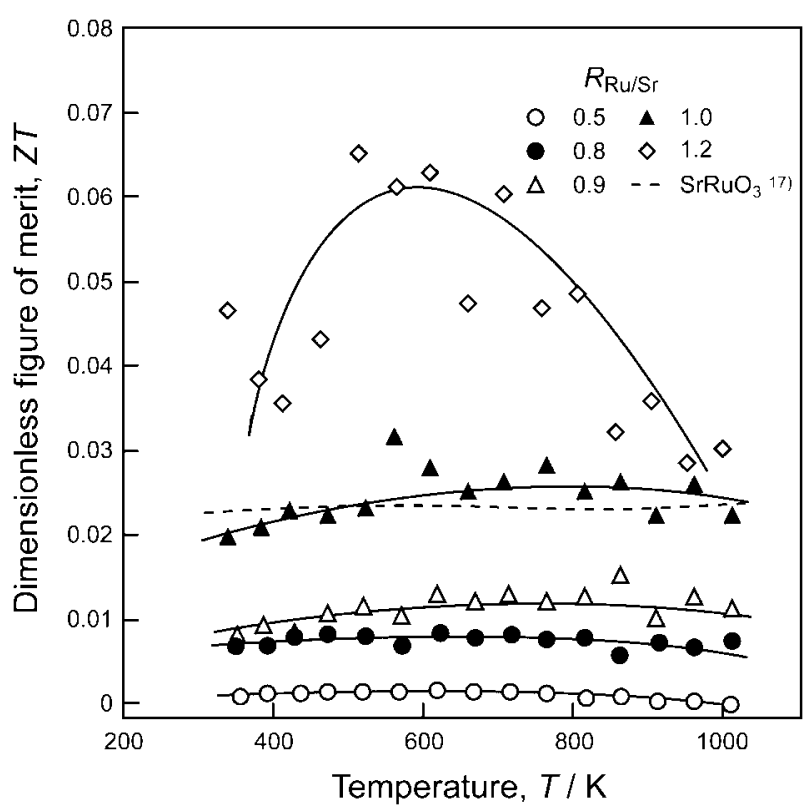

Fig. 9 Temperature dependence of dimensionless figure-of-merit (ZT) of $\mathrm{Sr}-\mathrm{Ru}-\mathrm{O}$ compounds.

0.06 at $600 \mathrm{~K}$. This value could be the highest among those of alkaline-earth ruthenate compounds, which was resulted from the combined effect of highest $\sigma$ and highest $S$ among these compositions. The $Z T$ was around 0.001 at $R_{\mathrm{Ru} / \mathrm{Sr}}=0.5$ and around $0.02-0.025$ at $R_{\mathrm{Ru} / \mathrm{Sr}}=1.0$. The value of $\mathrm{SrRuO}_{3}$ was slightly higher than that reported by Maekawa et al.

\section{Conclusion}

$\mathrm{Sr}-\mathrm{Ru}-\mathrm{O}$ compounds in various ratio of $\mathrm{Ru}$ to $\mathrm{Sr}\left(R_{\mathrm{Ru} / \mathrm{Sr}}\right)$ from 0.5 to 1.2 were prepared by spark plasma sintering (SPS) and the effect of composition on electrical conductivity $(\sigma)$, thermal conductivity $(\kappa)$ and Seebeck coefficient $(S)$ was investigated. $\mathrm{SrRuO}_{3}$ and $\mathrm{Sr}_{2} \mathrm{RuO}_{4}$ in a single phase were obtained at $R_{\mathrm{Ru} / \mathrm{Sr}}=1.0$ and 0.5 , respectively. The $\sigma$ increased with increasing $R_{\mathrm{Ru} / \mathrm{Sr}}$ at room temperature, exhibiting a metallic behavior at $R_{\mathrm{Ru} / \mathrm{Sr}}>0.5$ whereas that at $R_{\mathrm{Ru} / \mathrm{Sr}}=0.5$ slightly increased with temperature. The $S$ of $\mathrm{Sr}-\mathrm{Ru}-\mathrm{O}$ was around $20-40 \mu \mathrm{VK}^{-1}$ and increased with increasing $R_{\mathrm{Ru} / \mathrm{Sr}}$. The $S$ was almost independent of temperature at $R_{\mathrm{Ru} / \mathrm{Sr}} \geq 1.0$, whereas that at $R_{\mathrm{Ru} / \mathrm{Sr}}<1.0$ decreased significantly with increasing temperature. The $\kappa$ was around 2 to $7 \mathrm{Wm}^{-1} \mathrm{~K}^{-1}$ at room temperature and slightly increased with increasing temperature and $R_{\mathrm{Ru} / \mathrm{Sr}}$, whereas the $\kappa$ decreased with temperature at $R_{\mathrm{Ru} / \mathrm{Sr}}=0.5$. The highest dimensionless figure of merit $(Z T)$ was 0.06 at $R_{\mathrm{Ru} / \mathrm{Sr}}=1.2$ at $600 \mathrm{~K}$.

\section{Acknowledgements}

The authors are grateful to global COE program, JSPS Asian CORE program, Furuya Metal Co., Ltd. and Lonmin Plc. for financial support.

\section{REFERENCES}

1) C. S. Alexander, G. Cao, J. E. Crow and S. McCall: J. Alloy. Compd. 369 (2004) 2-4.

2) C. W. Jones, P. D. Battle, P. Lightfoot and W. T. A. Harrison: Acta Crystallogr., Sec. C 45 (1989) 365-367.

3) B. C. Chakoumakos, S. E. Nagler, S. T. Misture and H. M. Christen: Phys. B 241-243 (1998) 358-360.

4) B. J. Kennedy and B. A. Hunter: Phys. Rev. B 58 (1998) 653-658.

5) L. Capogna, A. P. Mackenzie, R. S. Perry, S. A. Grigera, L. M. Galvin, P. Raychaudhuri, A. J. Schofield, C. S. Alexander, G. Cao, S. R. Julian and Y. Maeno: Phys. Rev. Lett. 88 (2002) 076602.

6) X. D. Wu, S. R. Foltyn, R. C. Dye, Y. Coulter and R. E. Muenchausen: Appl. Phys. Lett. 62 (1993) 2434-2436.

7) J. S. Gardner, G. Balakrishnan and D. McK. Paul: Phys. C 252 (1995) 303-307.

8) L. Walz and F. Lichtenberg: Acta Crystallogr., Sec. C 49 (1993) 12681270.

9) G. Cao, S. McCall, M. Shepard and J. E. Crow: Phys. Rev. B 56 (1997) R2916-R2919.

10) K. Chandrasekaran, R. Vijiyaraghavan and U. V. Varadaraju: Mater. Chem. Phys. 56 (1998) 63-69.

11) F. Lichtenberg, A. Catana, J. Mannhart and D. G. Schlom: Appl. Phys. Lett. 60 (1992) 1138-1140.

12) P. Zheng, ZJ. Chen, NL. Wang, YP. Wang, ZQ. Mao and Y. Maeno: Acta Phys. Sinica 51 (2002) 655-658.

13) W. E. Bell and M. Tagami: J. Phys. Chem. 67 (1963) 2432-2436.

14) K. T. Jacob, K. T. Lwin and Y. Waseda: Mater. Sci. Eng. B 103 (2003) $152-161$.

15) N. Keawprak, R. Tu and T. Goto: Mater. Trans. 48 (2007) 1529-1533.

16) J. J. Randall and R. Ward: J. Am. Chem. Soc. 81 (1959) 2629-2631.

17) T. Maekawa, K. Kurosaki, H. Muta, M. Uno and S. Yamanaka: J. Alloy. Compd. 387 (2005) 56-59.

18) P. A. Cox, R. G. Egdell, J. B. Goodenough, A. Hamnett and C. C. Naish: J. Phys. C 16 (1983) 6221-6239.

19) H. Kobayashi, M. Nagata, R. Kanno and Y. Kawamoto: Mater. Res. Bull. 29 (1994) 1271-1280.

20) S. Ikeda, Y. Maeno and T. Fujita: Phys. Rev. B 57 (1998) 978-986.

21) P. B. Allen, H. Berger, O. Chauvet, L. Forro, T. Jarlborg, A. Junod, B. Revaz and G. Santi: Phys. Rev. B 53 (1996) 4393-4398.

22) Y. Noro and S. Miyahara: J. Phys. Soc. Japan 27 (1969) 518.

23) J. J. Neumeier, A. L. Cornelius and J. S. Schilling: Phys. B 198 (1994) 324-328.

24) S. Yamanaka, K. Kurosaki, T. Maekawa, T. Matsuda, S. Kobayashi and M. Uno: J. Nucl. Mater. 344 (2005) 61-66.

25) M. Shepard, P. F. Henning, G. Cao and J. E. Crow: J. Appl. Phys. 83 (1998) 6989-6991.

26) M. E. Fine and N. Hsieh: J. Am. Cer. Soc. 57 (1974) 502-503. 